Journal of Case Reports 2020;10(1):29-32

\title{
Acute Filarial Lymphangitis Presenting with Acute Abdominal Pain
}

\author{
Lalith Kumar Kanthala ${ }^{1}$, Samarasimha Reddy ${ }^{2}$, Samarjit Singh Ghuman ${ }^{3}$, Atul Kakar ${ }^{2}$, S Nundy ${ }^{1}$ \\ Departments of ${ }^{1}$ Surgical Gastroenterology, ${ }^{2}$ General Medicine, ${ }^{3}$ Radiology; Sir Gangaram Hospital, New Delhi -110060, India.
}

\section{Corresponding Author: \\ Dr. Atul Kakar \\ Email: atulkakar@hotmail.com}

This is an Open Access article distributed under the terms of the Creative Commons Attribution License (creativecommons.org/ licenses/by/3.0).

Received Accepted

Published

October 25, 2019

January 8, 2020

February 15, 2020

\begin{abstract}
Background: Filariasis usually presents as a hydrocoele, lymphoedema, chyluria or a groin lymphadenovarix due to lymphatic obstruction. Atypical presentation of lymphatic filariasis is not common even in endemic areas. We report an unusual presentation of acute filariasis in a patient who had features of peritonitis. Case Report: A 35 year old male from an endemic area for filariasis in India presented with acute lower abdominal pain, distension and scrotal swelling associated with intermittent high-grade fever and nonbilious vomiting. The contrast enhanced computed tomography of abdomen raised the suspiction of a disease involving the lymphatic system. Microfilarial larvae were detected in his peripheral blood smear. He improved with diethylcarbamazine and doxycycline. Conclusion: Surgeons should be aware of the rare and medically treatable causes of acute abdomen like filariasis to avoid the unnecessary surgical intervention. Careful screening of the patients through clinical, laboratory and imaging is of extreme importance to clear the diagnostic dilemma in such cases.
\end{abstract}

Keywords: Acute Abdomen, Lymphatic System, Microfilariae, Peritonitis, Testicular Hydrocele.

\section{Introduction}

Filariasis is an endemic infection caused by the nematodes Wucheraria bancrofti, Brugia malayi or Brugia timori which are transmitted by mosquitoes and seen in the tropical and sub-tropical regions of the world. It usually presents as a hydrocoele, lymphoedema, chyluria or a groin lymphadenovarix due to lymphatic obstruction [1]. We report an unusual presentation of acute filariasis in a patient who had features of peritonitis. He was planned for an exploratory laparotomy which was deferred as the CT imaging showed features of lymphatic obstruction and the diagnosis of filariasis was confirmed by a peripheral blood smear examination which detected microfilaria.

\section{Case Report}

A 35 year old male teacher who was a resident of Mahoba, Uttar Pradesh presented with acute lower abdominal pain, distension and a scrotal swelling for 1 week. He had episodes of intermittent highgrade fever and non-bilious vomiting over the same period. Evaluation done elsewhere included a CECT of the abdomen which revealed moderate free fluid, bilateral pleural effusions, pneumobilia with an over distended gallbladder and pericholecystic air suggestive of a perforation [Fig.1].

He was started on intravenous fluids and antibiotics (cefoperazone and metronidazole). An ultrasound guided abdominal drain was placed in the sub-hepatic region which had an output of $250 \mathrm{ml}$ of straw colored fluid on the first day. The next day he developed hypotension for which he was started on a noradrenaline infusion. After 48 hours, he developed blackish discolouration of his toes which was attributed to microvascular spasm as pulsations of the dorsalis pedis and posterior tibial arteries were easily felt [Fig.2]. His inotropes 
were gradually reduced and then stopped. During hospitalization the fever was persistent and his clinical condition did not improve. He was then referred to our hospital. At presentation, he was febrile and his blood pressure was 110/70 $\mathrm{mm} \mathrm{Hg}$. Ecchymotic patches were present over all the limbs with blackish discoloration of his toes in both feet with normal peripheral pulses. There was a blackish, crusty lesion $1 \times 1.5 \mathrm{~cm}$ in size over the medial aspect of his right ankle [Fig.3]. There was diffuse abdominal tenderness and guarding along with a tender, swollen erythematous scrotum. Arterial blood gas analysis revealed metabolic acidosis with respiratory compensation. He was admitted to the intensive care unit for an exploratory laparotomy. His complete blood picture at that time showed an elevated total leucocyte $(24,700 / \mu 1)$ and a low platelet count $(22,000 / \mu 1)$ with the renal and liver function tests being normal. The blood, urine and drain fluid cultures were negative. The drain fluid analysis showed an exudate with normal triglyceride levels. Ultrasonography of the scrotum was suggestive of bilateral epididymo-orchitis with a small hydrocoele with internal echoes. Lower limb Doppler examination was normal. The abdominal CECT was repeated after 7 days and showed low attenuating soft tissue thickening in the retroperitoneum suggestive of dilated lymphatics with thickening of the scrotal skin and spermatic cords which raised the suspicious of a disease involving the lymphatic system [Fig.4]. Serological tests for Leptospira and Scrub typhus were negative but microfilarial larvae were detected in the peripheral blood smear [Fig.5].

He was finally diagnosed as having atypical filariasis and treated with diethylcarbamazine $100 \mathrm{mg}$ thrice daily and the doxycycline. During the course of hospitalization his clinical condition improved, the scrotal swelling decreased in size, the abdominal drain output decreased and he was discharged. His two months showed improved ascites but a mild testicular swelling persists.

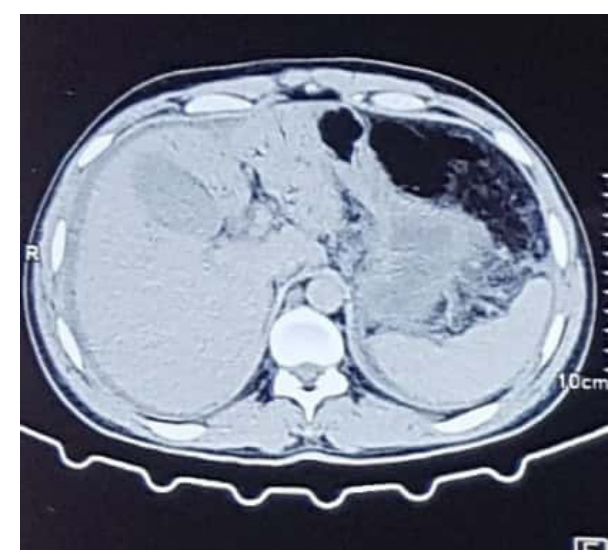

Fig.1: CECT abdomen: Haziness around the gallbladder fossa with a pericholecystic fluid collection.

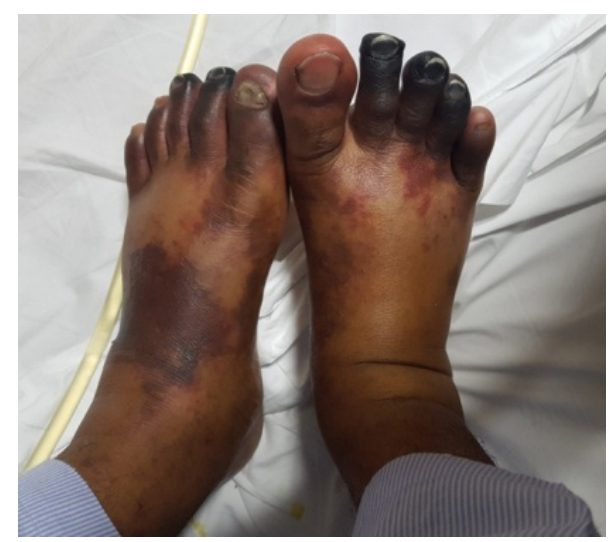

Fig.2: Peripheral gangrene due to micro-vascular spasm.

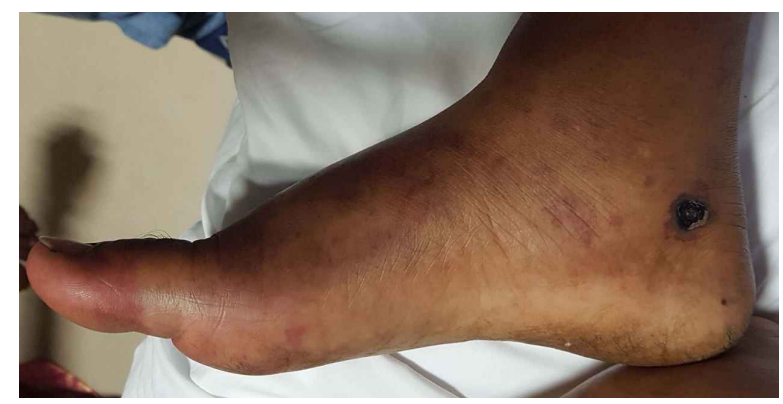

Fig.3: Black lesion on the right ankle.

\section{Discussion}

Lymphatic filariasis (LF) is one of the oldest and debilitating neglected tropical diseases. Approximately 120 million people worldwide are infected with the thread-like parasitic filarial 
worms causing lymphatic filariasis [2]. This tropical disease, found in regions of Asia, Africa, and Central and South America is spread by mosquitoes and causes episodes of acute and chronic inflammation, including elephantiasis.

Filariasis usually presents as a hydrocoele, orchitis, lymphoedema, chyluria or a groin lymphadenovarix due to lymphatic obstruction. It rarely presents as an acute abdomen. Our case had chylous peritonitis and epididymoorchitis as he presented with acute abdominal pain. Till now very few studies have reported this atypical presentation of filariasis [3,6]. Table 1 enumerates the various other unusual presentations seen by other authors. The standard imaging modality to visualize lymphatic vessels is lymphangiography which shows the extent of lymphatic vessel damage however the use of contrast can damage the inflamed vessels. Next best modality is contrast enhanced Computed Tomography (CECT). Mostly, the lymphatic system does not enhance with contrast on CT imaging but is observed as hypodense structures in the retroperitoneum which is suggestive of dilated lymphatic channels [2]. In our case, the abdominal CECT showed "significant low attenuating soft tissue in retroperitoneum, surrounding great vessels and bilateral iliac vessels extending into pelvis and presacral region suggestive of thickened dilated lymphatics with thickened scrotal skin and spermatic cords". These

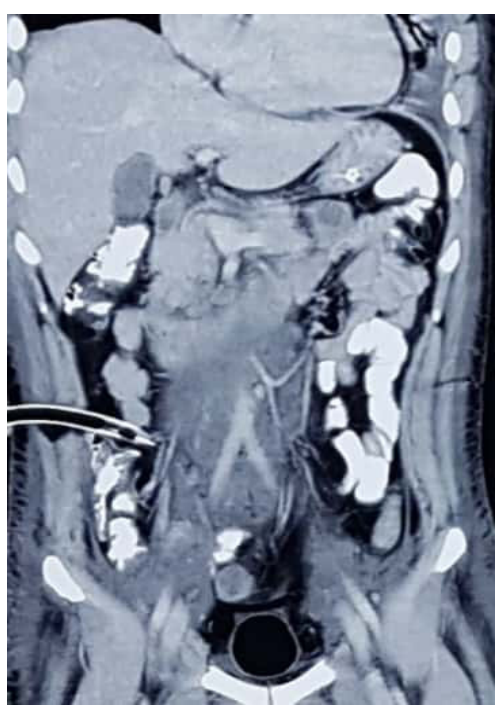

Fig.4: Low attenuating soft tissue in retroperitoneum surrounding bilateral iliac vessels.

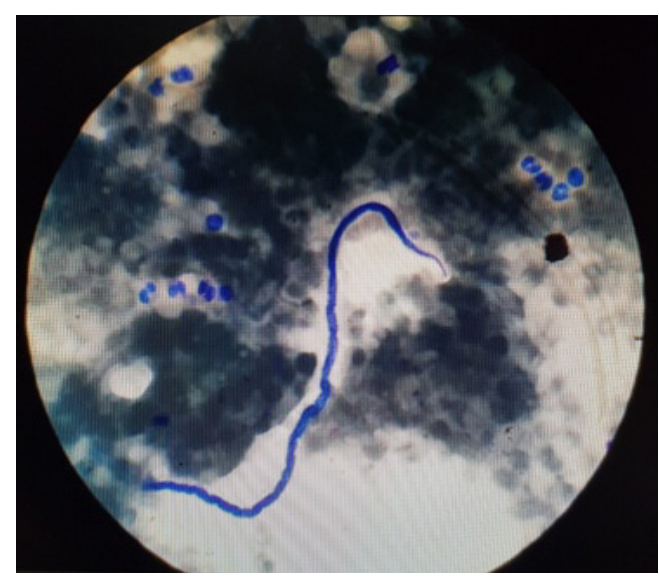

Fig.5: Microfilariae larva with curved body detected in peripheral blood smear of sample drawn at night time.

Table 1: Filariasis with atypical presentation.

\begin{tabular}{|l|l|l|l|l|}
\hline Author/ Country & History & Presentation & Diagnostic tool & Outcome \\
\hline $\begin{array}{l}\text { Mehta } \text { et al. } \\
\text { India }\end{array}$ & $\begin{array}{l}18 / \mathrm{M} \\
\text { Fever, vomiting, diffuse } \\
\text { abdominal pain. }\end{array}$ & Chylous ascites & $\begin{array}{l}\text { CT abdomen, USG } \\
\text { guided fluid aspiration- } \\
\text { microfilaria. }\end{array}$ & Improved with DEC. \\
\hline $\begin{array}{l}\text { Ahn } \text { et al. } \\
\text { South-America }\end{array}$ & $\begin{array}{l}22 / \mathrm{M} \\
\text { Fever, pain abdomen }\end{array}$ & $\begin{array}{l}\text { Chylous ascites, } \\
\text { lymphadenopathy }\end{array}$ & $\begin{array}{l}\text { CT thorax \& abdomen, } \\
\text { FNAC of lymph node - } \\
\text { microfilaria. }\end{array}$ & Improved with DEC. \\
\hline $\begin{array}{l}\text { Janssen } \text { et al. } \\
\text { Srilanka }\end{array}$ & $\begin{array}{l}22 / \mathrm{M} \\
\text { Painless scrotal swelling }\end{array}$ & Right testicular mass & $\begin{array}{l}\text { Right inguinal } \\
\text { orchiectomy-biopsy. }\end{array}$ & Improved. \\
\hline $\begin{array}{l}\text { Patne SCU et al. } \\
\text { India }\end{array}$ & $\begin{array}{l}37 / \mathrm{M} \\
\text { Painless scrotal swelling }\end{array}$ & Orchitis & FNAC-microfilaria. & Improved with DEC. \\
\hline $\begin{array}{l}\text { Vettoretto } \text { et al. } \\
\text { Italy }\end{array}$ & $\begin{array}{l}69 / \mathrm{M} \\
\text { Pain abdomen }\end{array}$ & Chylous ascites & $\begin{array}{l}\text { Laparotomy- chylous } \\
\text { fluid. }\end{array}$ & $\begin{array}{l}\text { Improved with lavage and } \\
\text { DEC. }\end{array}$ \\
\hline
\end{tabular}


findings raised the suspicion of filariasis and led us to perform a peripheral smear examination for microfilaria larvae and to defer the surgical intervention.

The definitive diagnosis for filariasis is established by laboratory investigations which detect circulating antigen in the blood and micro-filarial larvae in peripheral blood smears. Serologic tests for antibody detection have also been approved for routine use; however, they do not differentiate between the various types of filarial infections and often shows cross-reactivity with helminthic antigens. The standard approach for the management is treatment with anti-filarial agents. At the same time, it is crucial to evaluate for other concomitant infections and provide the treatment. Diethylcarbamazine is a CDC approved drug for treatment of filariasis. It has shown to kill approximately 50 percent of adult worms that further decreases the microfilaria burden [7]. It is accompanied by significant side effects in about half of the patients, including fever, headache, dizziness, and enlarged lymph nodes. Other drugs such as ivermectin, albendazole and doxycycline have demonstrated anti micro and macro-filarial activity. Doxycycline alone is more effective against the most common form of filariasis in Southeast Asia than the standard treatment, with significantly fewer side effects [2]. Doxycycline works by targeting a symbiotic bacterium, Wolbachia, which live inside the filarial worms. When the bacteria are killed by the antibiotic, then the worms also die. In our case, he was treated with DEC and doxycycline for 3 weeks with which he improved.

\section{Conclusion}

Atypical presentation of lymphatic filariasis as acute abdomen is not common even in endemic areas. We believe that careful screening of the patients through clinical, laboratory and imaging is of extreme importance to clear the diagnostic dilemma in such cases. Surgeons should be aware of this rare and medically treatable cause of acute abdomen to avoid the unnecessary surgical intervention.

Contributors: LKK: manuscript writing, literature review and patient management; SR, AK, SN: critical inputs into the manuscript and patient management; SSG: literature review, discussion and imaging. AK will act as a study guarantor. All authors approved the final version of this manuscript and are responsible for all aspects of the study.

Funding: None; Competing interests: None stated.

\section{References}

1. Fauci AS, Braunwald E, Isselbacher KJ, Wilson JD, Martin JB, Kasper DL. Harrison's Principles of Internal Medicine $15^{\text {th }}$ Ed. New York: McGraw Hill; 2001.pp.1238.

2. Tunkel AR, Glasor CA, Bloch KC, Sejvar JJ, Marra CM, Roos KL, et al. The management of encephalitis: clinical practice guidelines by the Infectious Diseases Society of America. Clinic Infect Dis. 2008;47:302-327.

3. Metha NN, Dalavi VS, Mehta NP. Filariasis presenting as acute abdominal pain: The role of imaging and imageguided intervention in diagnosis. Radiol Case Rep. 2016;10:1125.

4. Ahn PJ, Bertagnolli R, Fraser SL, Freeman JH. Distended thoracic duct and diffuse lymphangiectasia caused by bancroftian filariasis. AJR Am Roentgenol. 2005;185:1011-1014.

5. Janssen KM, Willis CJ, Anderson M, Gelnett MS, Wickersham EL, Brand TC. Filariasis OrchitisDifferential for acute scrotum pathology. Urol Case Rep. 2017;13:117-119.

6. Patne SCU, Das M, Katiyar R. Filarial orchitis due to Wuchereria bancrofti masquerading as testicular neoplasm. Am J Trop Med Hyg. 2016;95:497-498.

7. Klion AD, Ottesen EA, Nutman TB. Effectiveness of diethylcarbamazine in treating loiasis acquired by expatriate visitors to endemic regions: long-term followup. J Infect Dis. 1994;169:604-610. 